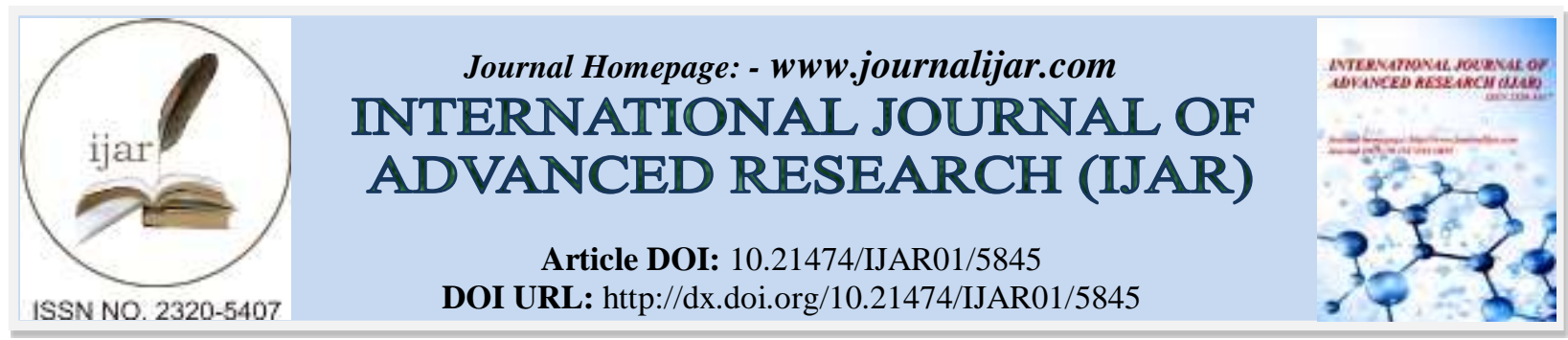

RESEARCH ARTICLE

\title{
DESIGNING AND DEVELOPING ALTERNATIVE EDUCATION MODALITIES TO IMPROVE THE LITERACY OF THE DUMAGATS.
}

\author{
${ }^{*}$ Valdez. Janet R. ${ }^{1}$, Galvez. Rosalyn ${ }^{2}$, Vistan. Alejandro Saratan ${ }^{3}$, Dr. Claudio Jr. Dayao ${ }^{4}$, Ryan. Vivar ${ }^{5}$ and \\ Elizabeth ${ }^{6}$.
}

1. La Consolacion University Philippines Graduate School.

2. La Consolacion University Philippines Student Affairs and Services.

3. La Consolacion University Philippines Quality Assurance Office.

4. Manila City Hall.

5. La Consolacion University Philippines Basic Education Department.

6. La Consolacion University Philippines Night College.

\section{Manuscript Info}

Manuscript History

Received: 12 September 2017

Final Accepted: 14 October 2017

Published: November 2017

Key words:-

alternative education modalities,

Dumagat, literacy.

\section{Abstract}

A comprehensive and functional definition of literacy formulated in 2008 by the United Nations Educational, Scientific, and Cultural Organization (UNESCO) included "the ability to read, write, comprehend, or embrace multiple skill domains to serve different purposes or to identify, interpret, create, communicate, and compute materials in different contexts." The definition ranked the Philippines 48th in the world according to the World Data Atlas in 2015 which configured a $96.6 \%$ adult literacy rate in the Philippines.

With globalization on the foreground of the $\mathrm{K}$ to 12 curriculum, the government opened new opportunities and challenges to the Filipinos. Alongside the governmental efforts in the delivery of service in education to the remotest areas shall include modalities apt for the indigenous culture, traditions, and mores. They should achieve the national goals of maximizing the fullest potentials of learners through the utilization of possible materials, pedagogical strategies, and alternative modalities.

With this in mind, the researchers proceeded to Norzagaray where an indigenous people called the Dumagats live. This study aimed to describe the literacy and the education modalities of the indigenous people in Norzagaray, Bulacan called the Dumagats through a case study of the government's alternative modalities delivered to the indigenous community.

Copy Right, IJAR, 2017,. All rights reserved.

\section{Introduction:-}

In 2008, the United Nations Educational, Scientific, and Cultural Organization (UNESCO) gave literacy a new meaning as "a process of learning that enables individuals to achieve personal goals, to develop their knowledge and potential, and to participate fully in the community and wider society." This definition shows a more comprehensive and functional context different from UNESCO's 1958 meaning of literacy which encompasses “ the 
ability to read, write, comprehend, or embrace multiple skill domains to serve different purposes or to identify, interpret, create, communicate, and compute materials in different contexts."

With these definitions, the Philippines was ranked $48^{\text {th }}$ in the world according to the World Data Atlas in 2015. The data configured a $96.6 \%$ adult literacy rate in the Philippines which was an increase from its rate in 2013 at $96.4 \%$. An interpretation of the total percentage describes the ability and understanding to read and write short and simple statement on the daily life of the population aged 15 and above. The term 'literacy' includes the ability to perform simple mathematical computations, otherwise known as 'numeracy.' The literacy rate is derived from the quotient after dividing the number of literates aged 15 years and above by the population of the corresponding age group, and multiplying the result by 100 . The rate poses challenges and opportunities for sustaining literacy and developing a literate environment.

It is in the interest of equality in improving literacy in the Philippines and designing, as well as, developing alternative education modalities that these researchers shared interest in exploring the educational experience of the Dumagats in a remote area in Norzagaray, Bulacan. With this in mind, the researchers proceeded to Norzagaray where an indigenous group of people called the Dumagats live. Norzagaray covers a portion of the Sierra Madre Mountain Range situated at the southeastern end of Bulacan bordering the Municipality of Montalban in Rizal Province, on the north by the Municipality of Doña Remedios Trinidad, on the west by the municipalities of Angat and Santa Maria, and on the southwest by the City of San Jose del Monte. More than one-third of the land area of Norzagaray falls within Angat Watershed that was delineated through Proclamation 71 dated March 10, 1927 covering a total area of some 62,310 hectares of the Sierra Madre in the Provinces of Bulacan and Nueva Ecija. The journey led the researchers to the 'Punduhan ng mga Dumagats' which is a ten-hectare property serving as a focal point for cultural and trading activities for the Agta-Bulos, Aeta or Dumagats tribes who had maintained their cultural traditions and customs by continuously living in the remotest place in the mountains. The Dumagats were named after naked people of the forest who had been referred to as the Aeta communities inhabiting the place. This geographical location of the Dumagats prevents the corruption of their indigenous customs, traditions, and livelihood which, on the other hand, prohibits literacy accessibility and growth.

Kral and Falk ( 2004) believe that the components of such a community form its capacity, and these components merge to achieve a state of well-being in the community. They include the intergenerational transmission of Indigenous knowledge, the skills and knowledge of alphabetic literacy practices and social capital.

\section{Statement of the Problem:-}

This study described the literacy and the education modalities of the indigenous people in Norzagaray, Bulacan called the Dumagats through a case study of the government's alternative modalities delivered to the indigenous community.

Specifically, the study finds the answer to the following questions:

1. What is the literacy rate of the Dumagats in Norzagaray, Bulacan, particularly the nineteen (19) families living within the communal habitat in Punduhan?

2. For what purposes and functions do people use reading and writing in everyday life in the community?

3. What governmental services should be added to improve the literacy among the Dumagats?

4. What alternative education modalities should be designed and developed to improve the literacy of the Dumagats?

\section{Methodology:-}

The research is constructed as a case study of the literacy practices of the Dumagats of Norzagaray, Bulacan using the ethnographic techniques of observation, document collection, and recording of conversations and interviews. Quantitative data include the results of the interviews: unstructured and semi-structured covering content areas on literacy history and intergenerational practices, literacy acquisition and learning, literacy use in everyday life, adult education, employment needs, and literacy use in everyday life. The procedures for data collection are as follows:

1. The researchers sought the help of the Municipality of Norzagaray who provided a guide to trudge the slopes of the Dumagats.

2. Data collection was done in a day where indigenous community members were sought for interviewing. The sampling was opportunistic, according to the availability of the respondents. Key informants, including their volunteer trained teacher, were sought for interviewing. 
3. Observations were made of community members engaging in everyday education practices and events.

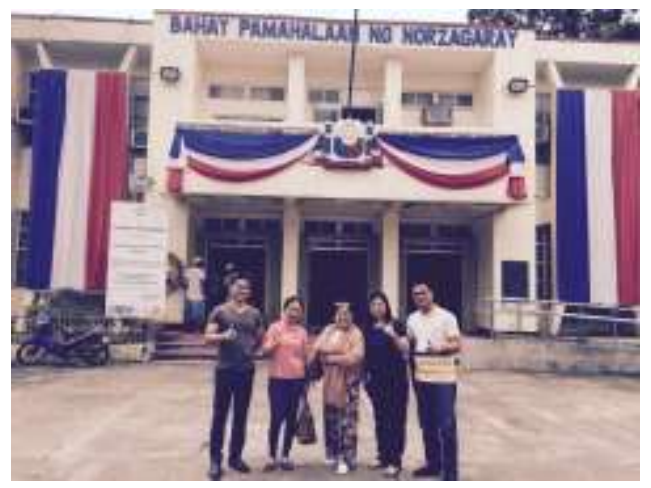

At the Municipality of Norzagaray and the Office of the Human Resources Head, where the researchers coordinated to seek permission to conduct the observation and interview and request a guide to bring them to the location of the Dumagats
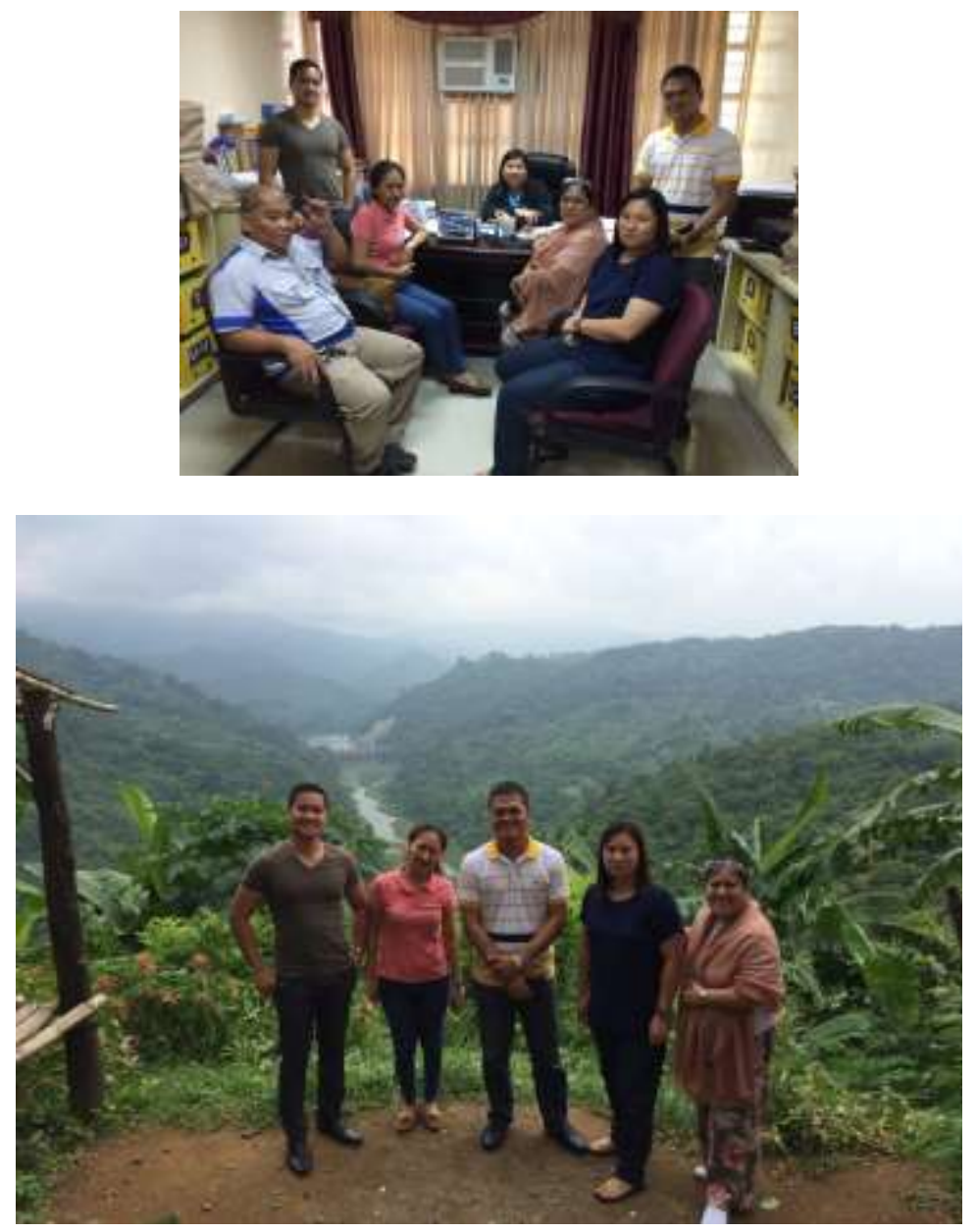


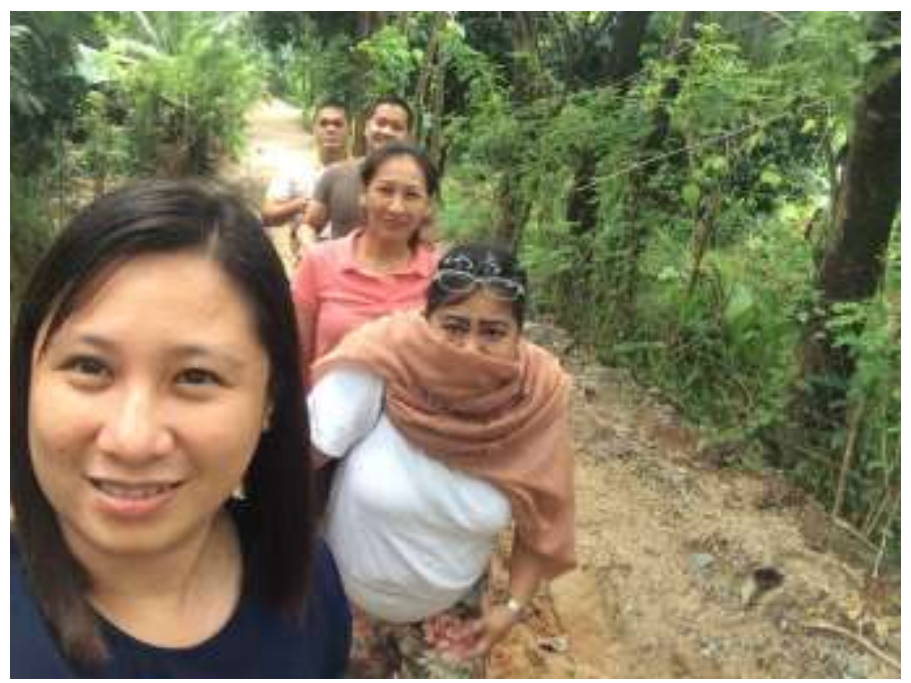

The researchers trudged through the terrains of the location of the Dumagats.

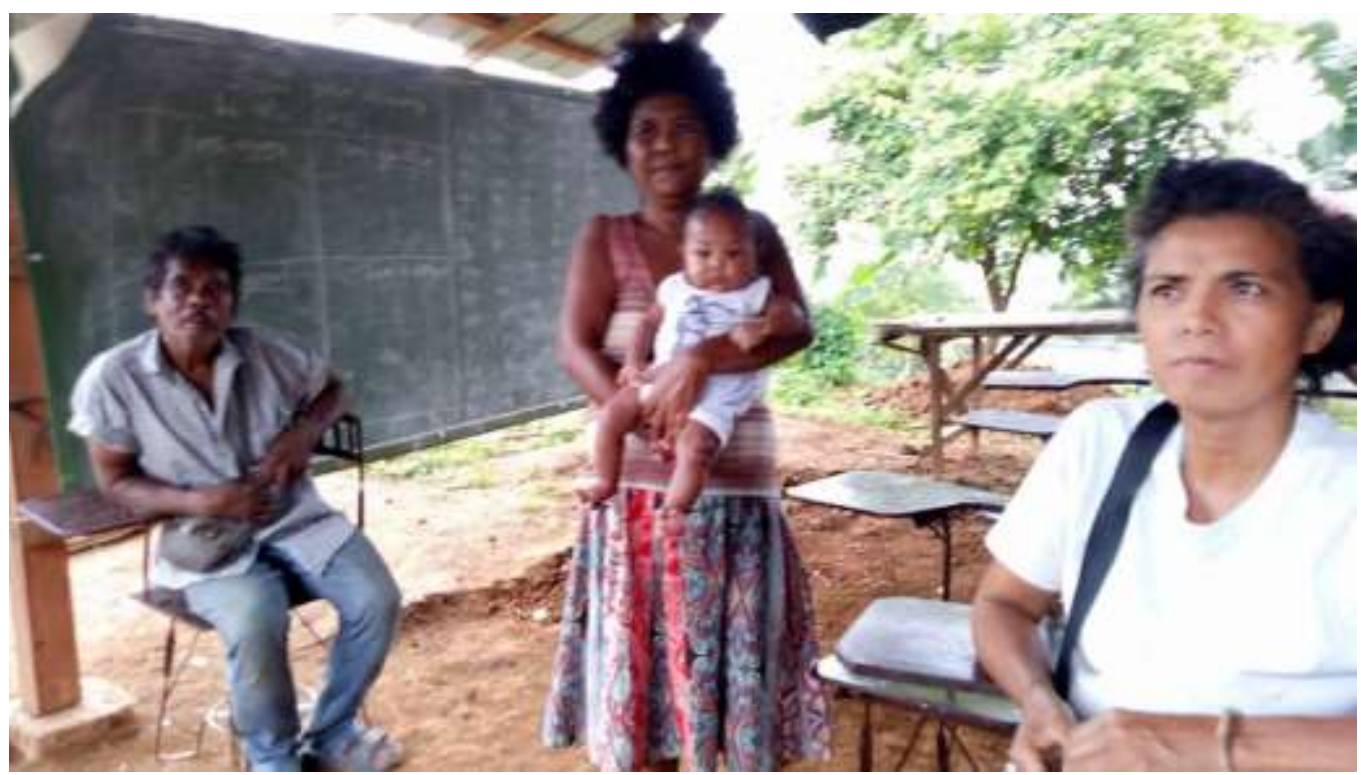

The volunteer trained teacher with other members of the Dumagat community. 

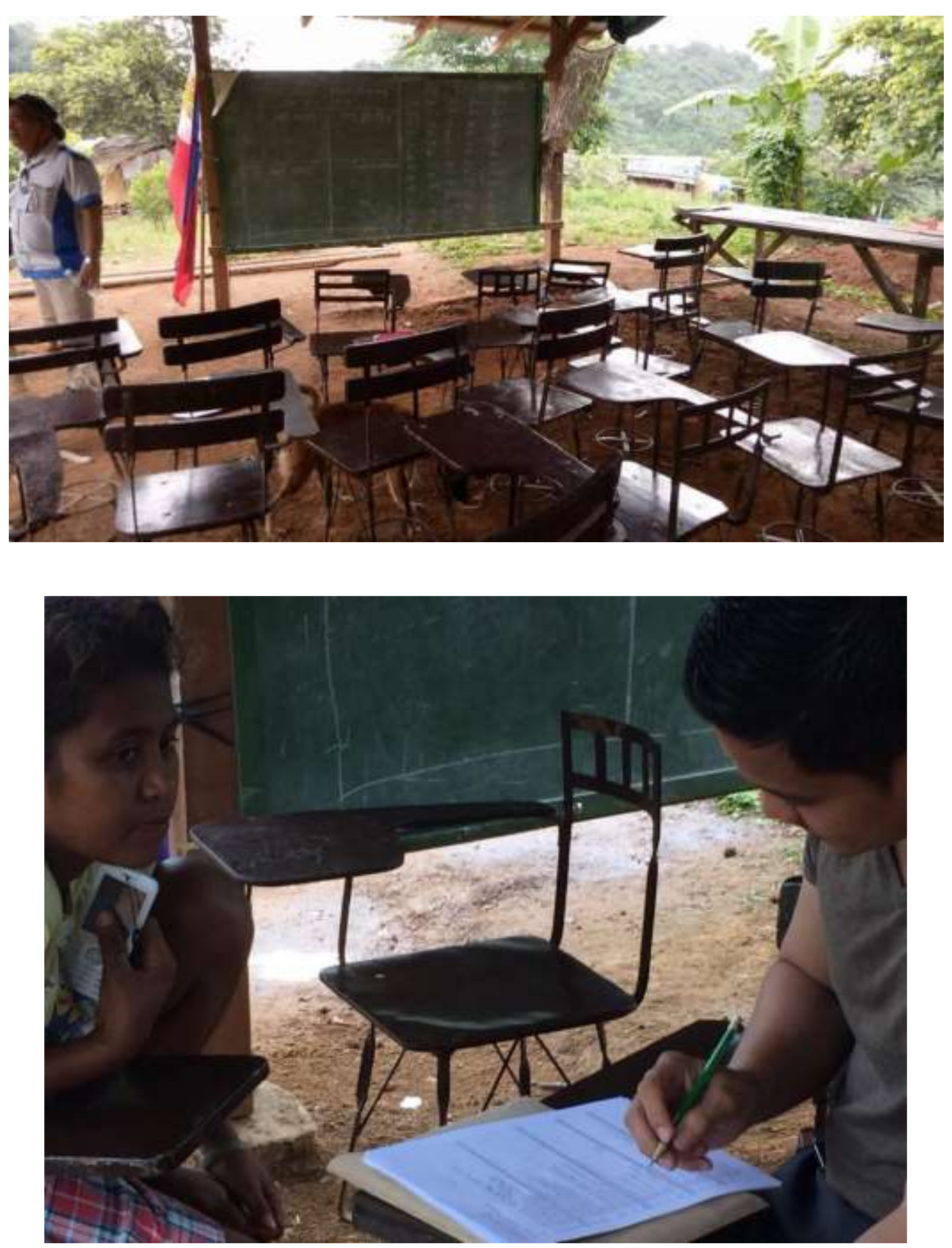

Data gathering 


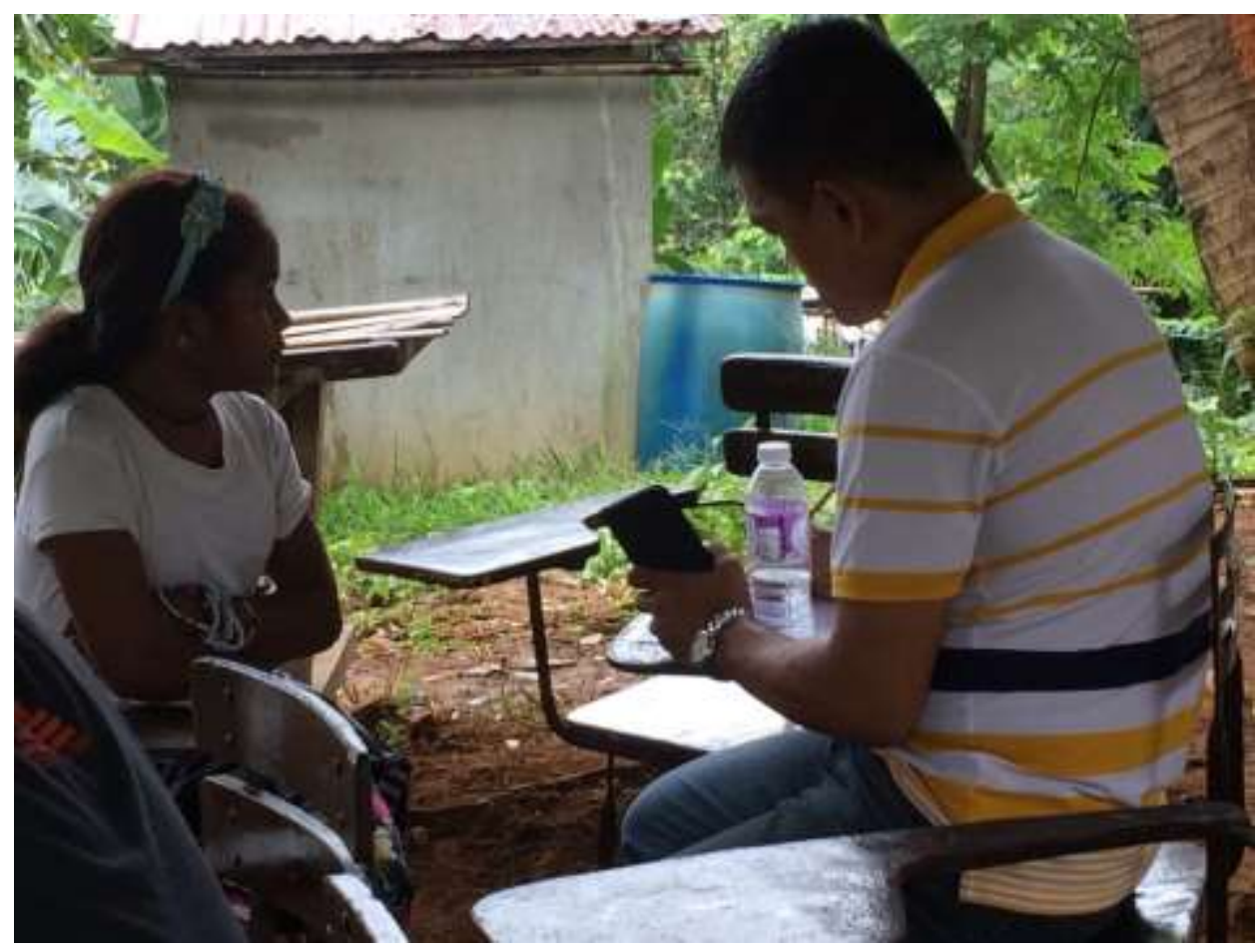

\section{Results and Discussions:-}

After the study, the researchers present the following findings:

\section{Problem 1:-}

The literacy rate of the Dumagats in Norzagaray, Bulacan, particularly the nineteen (19) families living within the communal habitat in Punduhan.

The researchers found out that at the time of the observation, four (4) out of the fifty-six (56) or 7.14\% of the total respondents, ten years and above, can read and write. Reading literacy is described as being able to read in Filipino or Tagalog and in English. The four respondents who can read and write were tested in their ability to read, comprehend, and provide answer to the questions in the questionnaire. Their literacy was evident. On the other hand, the fifty-two Dumagats, aged ten years and above, are being taught to identify the English alphabet, read English syllables and three-letter words.

\section{Problem 2:-}

Purposes and functions where the Dumagats use reading and writing in everyday life in the community The Dumagats can survive the day without the necessity to read and write. The remoteness of the community shields them from reading materials that will allow them to practice reading. Their desire to read and write in Filipino and English sprung from the desire not to get lost when they are away from home.

\section{Problem 3:-}

Governmental services that should be added to improve the literacy among the Dumagats

The Dumagats, just like any other Filipino citizen, deserve the governmental services fit for its citizenry; thus, the access to free basic education delivered to the entire country should, also, be received by this indigenous community. Formal education in a traditional school set-up should be enjoyed by this tribal community, especially its young population. Aside from formal education, alternative learning system should be provided with consistency and regularity to ensure the benefit of the population, especially its adults devoid of the skill and capacity to read and write. Regular teachers should be encouraged to cater to these indigenous people who thirst for knowledge and learning. 


\section{Problem 4:- \\ Alternative education modalities that should be designed and developed to improve the literacy of the Dumagats}

Improving the literacy of the Dumagats whose habitat is located in the remote area in the Sierra Madre Mountain Range is a challenge to the government. However, since this population belong to the $3.4 \%$ of the illiterate population, the effort to uplift their standard of living starts from the educational inputs derived from the government services. To deny them of equal access to education is a denial of their human right; therefore, alternative education modalities should be delivered to them. Alternative education modalities should include seminar, training, workshop on innovation and technological know-how in agriculture and other means of livelihood which would directly improve their literacy, and quality of life. The focus of the curriculum is on agriculture since their community is, still, in the process of developing their communal habitat after being displaced by the Angat watershed rehabilitation programs. They know how to clear their lands and plant crops using their crude tools. Training them in the use of modern farm instruments and teaching them with better technological innovations in agriculture improve their education; therefore, their livelihood. Aside from agriculture, the curriculum should include fishing and fishing technology. There are abundant indigenous materials from the forest trees that can be used for cottage industries or other means of livelihood. Agriculture, fishing, cottage industries, and other skills for lifelong learning should be the primary content of the specialized curriculum for the Dumagats. Furthermore, the need to learn on protecting wildlife and the forest, as well as, their ancestral lands should be part of the curriculum. Thus, instead of a classroom instruction, the teacher should explore other ways of discussing and teaching the contents of the curriculum

\section{Conclusion and Recommendations:-}

In the light of the following findings, the following conclusion and recommendations are drawn:

1. The remaining small population of Filipinos who does not possess the ability to read and write includes the Dumagats inhabiting Norzagaray, Bulacan. One of the factors which hinders them from acquiring free basic education is their geographical location amounting to the lack of accessible school system within the area.

2. Without accessibility to free public education, the government provides the Dumagats with teachers who deliver the Alternative Learning System (ALS) for both adult and young learners.

3. The ALS teachers come to the community once a month to ensure the acquisition of the basic literacy skills or the ability to read and write. As a way to continue on the role of the ALS teachers to the community, a literate adult teacher-volunteer assists their daily practices and lessons.

4. With the absence of a regular teacher and the presence of an ALS teacher who could teach in the community once a month, the government should design and develop alternative education modalities that will cater to the educational needs of the indigenous communities like the Dumagats.

5. The Dumagat teachers should be creative in developing and designing alternative education modalities that ensure real-life and lifelong knowledge and skills of the Dumagat learners.

6. Alternative education modalities, including seminars and trainings, should be explored to ensure the full grasp of the curriculum which focuses on innovative and scientific agriculture, fishing, and home industries utilizing their indigenous skills and materials.

7. Instructional materials should include tangible, easy-to-read, culturally-sensitive modules with or without the use of technology.

\section{References:-}

1. Huang, S., \& Liu, S. (2016). Discrimination and incorporation of Taiwanese indigenous Austronesian peoples. Asian Ethnicity, 17(2), 294-312. doi:10.1080/14631369.2015.1112726

2. Kral and Falk (2004). What is all that learning for? Indigenous adult English literacy practices, training, community capacity and health. Commonwealth of Australia.

3. McKAY, T. (2017). BUILDING A COMMUNITY OF LIFELONG LEARNING. Phi Kappa Phi Forum, 97(2), $10-13$.

4. McKeough, A. (2006). Understanding Literacy Development : A Global View. Mahwah, N.J.: Routledge

5. Mei Kuin, L., McNaughton, S., Amituanai-Toloa, M., Turner, R., \& Hsiao, S. (2009). Sustained Acceleration of Achievement in Reading Comprehension: The New Zealand Experience. Reading Research Quarterly, 44(1), $30-56$. 
6. NGWARU, J. M. (2017). MULTI-LITERACIES PEDAGOGY DESIGN: THE CASE OF FOCUSED ETHNOGRAPHIC RESEARCH AND CATALYTIC VALIDITY IN LITERACY DEVELOPMENT. International Journal Of Humanities, Arts \& Social Sciences, 3(2), 31-43. doi:10.20469/ijhss.3.20001-2

7. Soler, J., Wearmouth, J., \& Reid, G. (2002). Contextualising Difficulties in Literacy Development : Exploring Politics, Culture, Ethnicity and Ethics. London: Routledge

8. Retrieved from Knoema World Data Atlas https://knoema.com/atlas/Philippines/topics/ Education/Literacy/Adult-literacy-rate on August 27, 2017. 